\title{
Automated estimation of sodium, potassium, and calcium using the Eppendorf flame photometer
}

\author{
A. M. BOLD, R. J. HURST, AND R. R. MCSWINEY \\ From the Department of Chemical Pathology, \\ St. Thomas's Hospital Medical School, London
}

SYNOPSIS An Eppendorf flame photometer may be used to estimate sodium, potassium, and calcium in plasma which has been automatically sampled and diluted. Readings may be automatically recorded by feeding the output from the photomultiplier into a sensitive recorder. This method estimates 60 samples an hour, using approximately $0.12 \mathrm{ml}$. plasma per estimation. The accuracy of the method is discussed.

Requests for the estimation of sodium, potassium, and calcium in plasma comprise a considerable proportion of the work of a clinical chemistry laboratory. An ordinary flame photometer has been adapted to the automated estimation of these metals, resulting in considerable saving of time, without loss of accuracy. Samples are diluted and fed to the flame photometer by an AutoAnalyzer sampling module and proportioning pump module. Output from the flame photometer is recorded graphically.

\section{APPARATUS}

Figure 1 shows a flow diagram for the apparatus using a standard AutoAnalyzer sampler and pump, an Eppendorf flame photometer, and a Kipp micrograph recorder, model B.D.1. The debubbling chamber (Fig. 2) was made

Received for publication 14 August 1964.

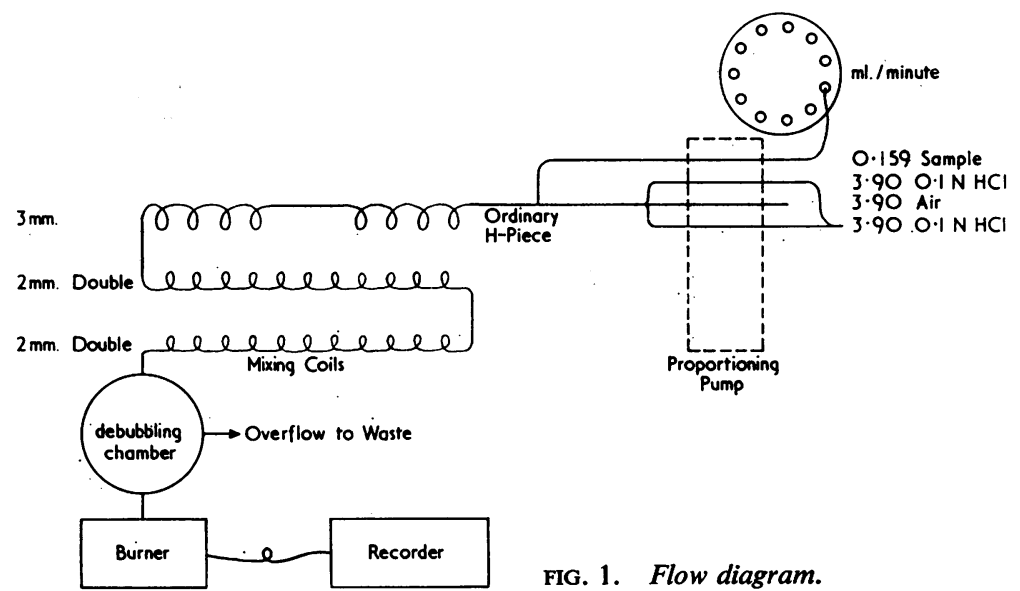

from a $100 \mathrm{ml}$. flask, and contains a funnel made from glass tubing with an internal bore of $3 \mathrm{~mm}$., widened to a maximum of $12 \mathrm{~mm}$. The recorder is plugged into a switched jack socket, which is wired in series with the earth side of the flame photometer galvanometer (Fig. 3) ${ }^{1}$. In parallel with the recorder input is a variable resistance used to match the full-scale deflection of the recorder to that of the flame photometer galvanometer. We have also used an Advance Volstat mains voltage stabilizer (not

${ }^{1}$ The most recent model of the Eppendorf flame photometer incorporates a socket outlet for a recorder; we have not tested this model. 


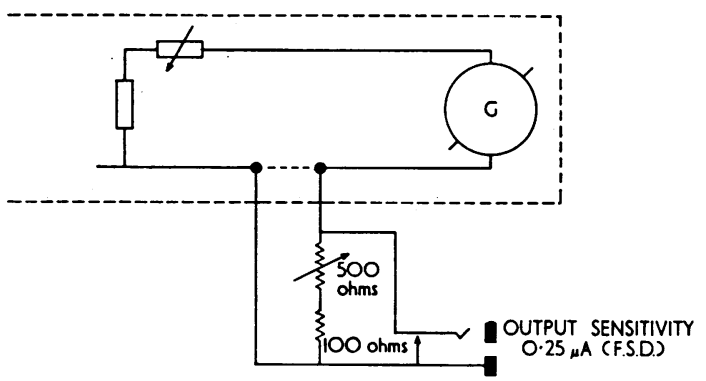

FIG. 3. Diagram to show the insertion of the jack socket and the variable resistance in the flame photometer circuit.

included in the flow diagram) for the recorder to improve stability.

\section{METHOD}

Plasma ${ }^{2}$, anticoagulated with lithium heparin (sodium free), is sampled at a rate of 60 per hour, diluted approximately $1: 50$ with $0 \cdot 1 \mathrm{~N}$ hydrochloric acid, segmented with air and thoroughly mixed. The air bubbles escape in the funnel of the debubbling chamber where some of the segments are pooled. Some of the mixture is aspirated into the flame photometer atomizer by the normal sampling tube.

The flame photometer is turned on in the normal manner. Gas pressure settings are chosen to ensure maximum plateau readings with fixed concentration of the metal to be estimated. For sodium and potassium, propane at a pressure of $180 \mathrm{~mm}$. of water and air at 0.5 $\mathrm{kg} . / \mathrm{cm}^{2}$, were used on our apparatus; for calcium, acetylene at a pressure of $540 \mathrm{~mm}$. of water replaces propane, with the same air pressure. The recorder's current selector is set to give a full-scale deflection with a current of $0.25 \mu \mathrm{A}$. A chart drive speed of $360 \mathrm{~mm}$./hour is satisfactory.

Standard solutions containing 100 to $160 \mathrm{mEq} . / 1$. of sodium, 2.5 to $7.5 \mathrm{mEq}$./1. of potassium, and 5 to 15 $\mathrm{mg} . / 100 \mathrm{ml}$. of calcium are used. For sodium and potassium greater accuracy is obtained if all the standard solutions contain both metals. For estimation of calcium, all standard solutions are made up to contain 140 $\mathrm{mEq}$./1. of sodium in addition to calcium. This is important with the Eppendorf flame photometer because its interference filter measures the emission due to calcium oxide at $620 \mathrm{~m} \mu$ and there is some interference from sodium. Errors due to the variation in sodium concentration in plasma may be neglected (e.g., if the sodium concentration is as low as $120 \mathrm{mEq} . / 1$., the measured calcium concentration will be $0.14 \mathrm{mg} \%$ too low).

Before estimations are made, the apparatus should be warmed up by spraying a solution containing sodium, potassium, and calcium through the flame for about 30 minutes. Even after a 30-minute warm-up, slow changes in the performance of the apparatus may occur. In our experience, a steady downward drift, of the order of $5 \%$

${ }^{2}$ Urine may be used for sodium or potassium estimation, though a preliminary manual dilution may sometimes be necessary. The accurate automated estimation of calcium in urine presents special problems.

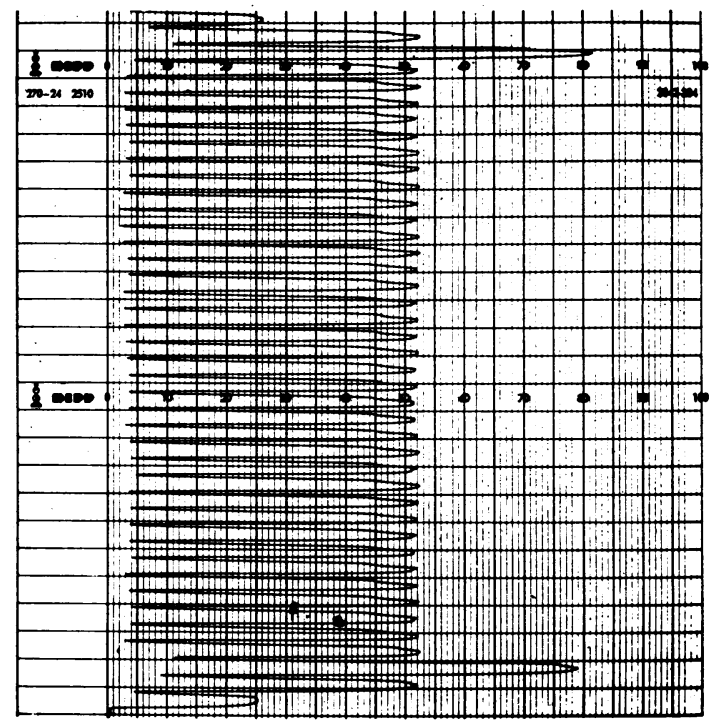

FIG. 4. Photograph of record of potassium estimations. On the right-hand side, standard solutions containing $2 \cdot 5$, 5 , and $7.5 \mathrm{mEq} . / 1$. of potassium are recorded, followed by repeated estimation of one plasma. On the left, the standard solutions have been repeated in reverse order. They show the small overshoot that occurs when an aqueous solution follows plasma, and also the small extent of contamination. The chart record reads from right to left.

in an hour, may occur for sodium and calcium; the change is much less for potassium. It is not satisfactory to use an aqueous standard solution to check stability, since the change from protein-containing solutions to aqueous solutions is followed by a temporary overshoot (Fig. 4). However, the extent of the drift may readily be estimated by running a 'reference' plasma immediately after the standard solutions, and at intervals, for example, after each batch of five plasmas. If a change in the reference plasma occurs, the intervening plasma values should be appropriately corrected. Plasma unwanted by the blood bank, or a mixture of surplus sera and plasmas from the laboratory may be used as 'reference' plasma. A batch of $500 \mathrm{ml}$. will last many weeks if a preservative, such as sodium merthiolate, is added.

Three important practical points must be mentioned:-

1 The internal jet of the flame photometer atomizer should always be cleaned before use. The hydrochloric acid diluent helps to keep it clean during use.

2 Plasma should be free from liquid paraffin, and any particles of fibrin must be removed, because the sampling line, which is of small bore, may become partially blocked.

3 The pick-up tubing from the flame photometer should dip well below the top of the funnel in the debubbling chamber and to one side of the escaping bubbles (Fig. 2). When this is done, the froth has not proved troublesome. The addition of froth suppressants causes error by affecting the readings from plasma and aqueous solutions differently. 


\section{TESTING THE METHOD}

STANDARD CURVES Figures 4 to 6 show standard curves for the ranges 100 to $160 \mathrm{mEq}$./1. of sodium, $2 \cdot 5$ to $7 \cdot 5$ $\mathrm{mEq}$./1. of potassium, and 5 to $15 \mathrm{mg}$. $/ 100 \mathrm{ml}$. of calcium. The curves for potassium and calcium are linear, that for sodium is not. The deflections obtained enable differences in concentration of less than $1 \%$ to be distinguished readily.

REPRODUCIBILITY Sodium, potassium, and calcium were estimated on one plasma 25 times. After each batch of five, a reference plasma was run, and appropriate corrections made for any change in the reference reading. The coefficients of variation were as follows: sodium $0.5 \%$; potassium $0.6 \%$; calcium $0.6 \%$. Repeated tests with different plasmas showed similar results (Figs. 4 and 5).

CONTAMINATION One common problem in auto-analysis occurs when a solution containing an abnormally high concentration of the substance to be estimated is incompletely washed out causing an error in the succeeding estimation. To test this effect, standard solutions and plasmas containing high and low concentrations of sodium, potassium, and calcium were estimated in duplicate pairs. The extent of contamination was taken as the difference in reading between the first and second of a pair (Fig. 6). These tests showed that the maximal effects of contamination likely to be encountered in plasma were: sodium $\pm 1 \mathrm{mEq} . / 1$., potassium $\pm_{-} 0.05 \mathrm{mEq} . / 1$, calcium $\pm 0.1 \mathrm{mg} \%$.

EXTENT OF PROTEIN INTERFERENCE Twenty plasmas, normal and abnormal, were estimated in duplicate by the automated flame photometer. The results were compared with those obtained by manual estimation of duplicate dilutions of the same plasmas after removal of protein. Protein was precipitated by adding $24 \mathrm{ml}$. of $5 \%$ trichloroacetic acid to $1 \mathrm{ml}$. of plasma. Potassium and calcium were estimated manually on the supernatant obtained after centrifuging; sodium was estimated on the supernatant fluid further diluted 1:10 with distilled water. Standard solutions were made by adding the appropriate amount of trichloroacetic acid to the standard solutions used for the corresponding automated estimations. The effect of protein was to depress all readings: sodium by $3.3 \pm 0.69 \mathrm{mEq} . / 1$. (mean and standard deviation), potassium by $0.1 \pm 0.09 \mathrm{mEq}$. $/ 1$., and calcium by $0.3 \pm$ $0.18 \mathrm{mg} \%$.

COMPARISON WITH MANUAL ESTIMATION The same 20 plasmas mentioned above were estimated on the same flame photometer by the normal manual method. For this, duplicate dilutions of plasma in distilled water were made, 1:25 for potassium and calcium, 1:250 for sodium. The standards used for the automated estimations were diluted similarly, and employed as the 'manual' standards.

The differences were for sodium $-0.2 \pm 0.8 \mathrm{mEq} . / 1$. (mean and standard deviation), for potassium +0.05 $\pm 0.09 \mathrm{mEq} . / 1$., and for calcium $+0.04 \pm 0.1 \mathrm{mg} \%$. These small differences are probably owing to the differences in dilution used.

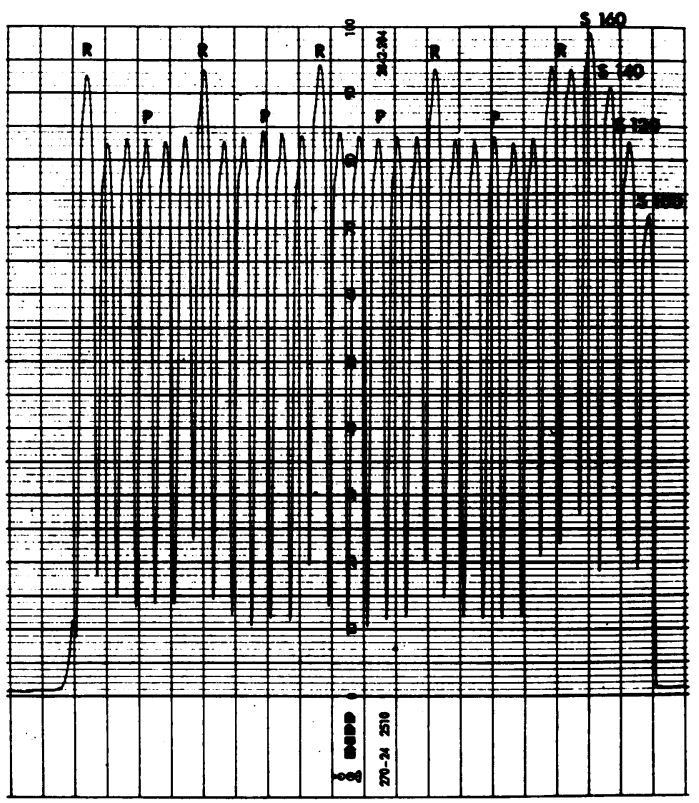

FIG. 5. Photograph of the record of sodium estimations. $S 100$ to $S 160$ show the recording of standard solutions containing 100 to $160 \mathrm{mEq} . / 1 . R$ is the reference plasma, $P$ the test plasma. The chart record reads from right to left.

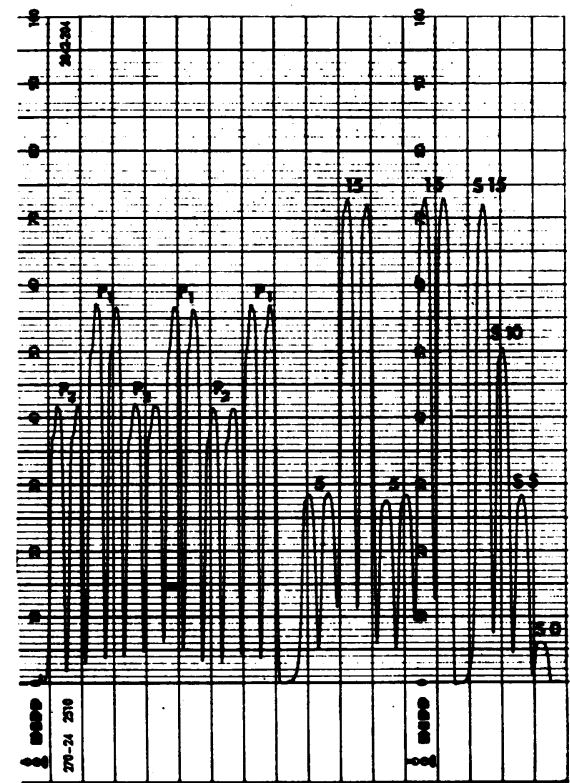

FIG. 6. Photograph of the record of calcium estimations. SO to S15 are standard solutions containing 0 to $15 \mathrm{mg} . \%$ of calcium, all containing $140 \mathrm{mEq}$./1. sodium. The extent of contamination occurring when solutions and plasma containing high and low concentrations of calcium are alternated is shown. The chart record reads from right to left. 


\section{DISCUSSION}

Unlike the automated flame photometer produced by Autotechnicon (Isreeli, Pelavin, and Kessler, 1960), the Eppendorf flame photometer does not employ an internal standard. In our experience, this flame photometer is sufficiently stable for satisfactory automatic analysis (Fig. 4), provided the practical precautions mentioned previously are observed. Small, slow changes in performance may occur; errors due to this may be corrected by observing the changes in a reference plasma, as mentioned above.

This method does not employ a dialyser, although for sodium and potassium one could be incorporated if desired. The omission of a dialyser reduces the cost and saves time in operation and maintenance. The absence of a dialyser, however, does cause the protein interference effect, mentioned above. This effect occurs even in a dilution of $1: 50$, and is probably at least partly due to diluted plasma's greater viscosity than aqueous solutions (Fawcett and Wynn, 1961). Our results for protein interference are in good agreement with those reported by Fawcett and Wynn, for calcium. Bergström and Hultman (1962) found a larger protein interference effect on sodium than is reported here: presumably this is due to the variation in performance of different atomizers to which they refer. Flame photometric methods which estimate sodium, potassium, and calcium on plasma from which protein has not been removed require interpretation in the light of an appropriate normal range. An investigation in our own department on a hundred normal fasting subjects showed the following normal ranges (to include $98 \%$ of subjects) with mean and standard deviation.

\section{TABLE}

$\begin{array}{ll}\text { Sodium } & 129-142 \mathrm{mEq} . / 1 .(135 \pm 2.7) \\ \text { Potassium } & 3.3-4.5 \mathrm{mEq} \cdot / 1 .(3.9 \pm 0.27) \\ \text { Calcium } & 8.5-10.1 \mathrm{mg} \%(9.3 \pm 0.35)\end{array}$

Mohun and Cook (1962) who also estimated plasmas by flame photometry without deproteinization, found a normal range (98\%) of 126 to $144 \mathrm{mEq} . / 1$. for sodium and 3.6 to $5.3 \mathrm{mEq} . j 1$. for potassium. Wootton, King, and Smith (1951) give $98 \%$ ranges of 133 to $152 \mathrm{mEq} . / 1$. for sodium and 3.5 to 5.6 $\mathrm{mEq} . / 1$. for potassium. McIntyre (1961), using deproteinized plasma for flame photometry, gives a normal range ( $98 \%$ ) of 9.8 to $11.0 \mathrm{mg}$. \% for calcium. Copp (1963), using an accurate E.D.T.A. method, found a range ( $98 \%$ ) of 8.6 to $10.2 \mathrm{mg} . \%$ for calcium.

These examples from the literature on normal ranges underline the desirability of determining the normal range for the method and apparatus used in each laboratory.

The error caused by the variation in protein interference in different plasmas is likely to be of no clinical significance for sodium and potassium (see the standard deviation in the Table), but is larger for calcium. Here borderline figures should be treated with caution and where possible the filterable or ionized calcium (Rose, 1957) should be determined.

The desirable standard of accuracy for the estimation of sodium, potassium, and calcium is not universally agreed. It is reasonable that such a standard should be related to the width of the normal range. Zwart Voorspuij and Van der Slik (1964) suggested that the ratio of the standard deviation of a particular estimation in normal subjects to the standard deviation of the reproducibility of this estimation should have a value of at least $3: 1$. If the above standard deviations for normal sodium, potassium, and calcium are calculated as percentages and the figures for reproducibility by this method, quoted above, are used, the ratios obtained are approximately $4: 1$ for sodium, more than $10: 1$ for potassium, and $7: 1$ for calcium.

We are working on further modifications to the flame photometer which will enable potassium and sodium to be estimated simultaneously.

We wish to thank Miss Joan Dewe who drew the figures and the members of the Photographic Department, St. Thomas's Hospital Medical School, who took the photographs.

\section{REFERENCES}

Bergström, J., and Hultman, E. (1962). Lcincet, 1, 1132. Copp, D. H. (1963). J. Lab. clin. Med., 61, 1029.

Fawcett, J. K., and Wynn, V. (1961). J. clin. Path., 14, 463.

Isreeli, J., Pelavin, M., and Kessler, G. (1960). Ann N.Y. Acad. Sci., $87,636$.

McIntyre, I. (1961). Advanc, clin. Chem., 4, 1.

Mohun, A. F., and Cook, I. J. Y. (1962). Lancet, 1, 778.

Rose, G. A. (1957). Clin. chim. Acta., 2, 227.

Wootton, I. D. P., King, E. J., and Smith, J. M. (1951). Brit. med. Bull. 7. 307.

Zwart Voorspuij, A. J., and Van der Slik, W. (1964). Clin. chim. Acta., 9. 99. 